\title{
GMR
}

\section{Tumor necrosis factor-like weak inducer of apoptosis association with proliferative diabetic retinopathy and promotes proliferation and collagen synthesis in retinal ARPE-19 cells}

\author{
D.Y. Chen and G.F. Su \\ Department of Ophthalmology, The Second Affiliated Hospital, Jilin University, \\ Changchun, China \\ Corresponding author: G.F. Su \\ E-mail: guanfsu@163.com
}

Genet. Mol. Res. 15 (1): gmr. 15016920

Received August 1, 2015

Accepted November 28, 2015

Published March 18, 2016

DOI http://dx.doi.org/10.4238/gmr.15016920

\begin{abstract}
Chronic inflammation develops in the retinal microvasculature under sustained hyperglycemia and is implicated in the pathogenesis of diabetic retinopathy. Tumor necrosis factor-like weak inducer of apoptosis (TWEAK) and its receptor Fn14 have been reported to promote proinflammatory cytokines, which are involved in the pathogenesis of proliferative diabetic retinopathy (PDR). It is therefore possible that the TWEAK/Fn14 pathway can play a regulatory role in PDR. In the present study, we examined the expression of TWEAK and Fn14 in vitreous fluid from PDR patients. To confirm the correlation between the TWEAK expression and clinical pathological characteristics of PDR, we investigated the regulatory role of the TWEAK/Fn14 pathway in cell proliferation and collagen synthesis in retinal ARPE-19 cells. The results demonstrated that vitreous fluid from patients with PDR had higher levels of TWEAK and Fn14 than that from T2DM patients without PDR, thus suggesting an important regulatory role of TWEAK/Fn14 signaling in the pathogenesis of PDR. Furthermore, overexpression of TWEAK in ARPE-19 cells also promoted
\end{abstract}


proliferation of and collagen synthesis in these retinal cells. It is possible that TWEAK/Fn14 upregulation in PDR may contribute to PDR progression by promoting the proliferation or fibrosis of retinal cells.

Key words: TWEAK; Proliferative diabetic retinopathy; Proliferation; Collagen synthesis; Retinal ARPE-19 cells

\section{INTRODUCTION}

Diabetic retinopathy (DR) is ranked as the most severe ocular complication of diabetes mellitus (DM) and remains a major cause of vision loss in many countries (Rizyal, 2004). Chronic inflammation develops in the retinal microvasculature under sustained hyperglycemia (Abu El-Asrar et al., 1992; Meleth et al., 2005) and is implicated in the pathogenesis of diabetic retinopathy. Proliferative DR (PDR) is followed by recurrent vitreous hemorrhages, traction retinal detachment, retinal and vitreous fibrosis, and optic nerve atrophy, which finally lead to severe visual impairments (Abu El-Asrar et al., 2006; Bhavsar, 2006; Lim et al., 2008). Retinal neovascularization (RNV) is the most striking characteristic of PDR (Du et al., 2014) and involves various angiogenic factors such as cytokines, inflammatory cells, and growth factors (Adamis, 2002; Abu El-Asrar et al., 2006; Patel et al., 2006). Previous studies have also emphasized the role of vascular endothelial growth factor (VEGF) and other factors with angiogenic properties in the pathogenesis of PDR (Citirik et al., 2012; Mohan et al., 2012; Pennock and Kazlauskas, 2012). It is known that disturbances or functional imbalance of the immune system as well as activation of vascular proliferation contribute to the pathogenesis of PDR (Murugeswari et al., 2008; Kowluru et al., 2010; Suzuki et al., 2011; Symeonidis et al., 2011). However, the interactions between the pro/anti-inflammatory cytokines and angiogenic factors in PDR remain to be explored.

Several members of the tumor necrosis factor (TNF) superfamily have recently been found to regulate inflammation and neovascularization (Burkly et al., 2007; Sethi et al., 2009; Zhang and $\mathrm{Li}, 2012$ ). In particular, TNF-like weak inducer of apoptosis (TWEAK) activates the nuclear factor$\kappa B$ signal (Polavarapu et al., 2005) transduction pathway by binding to fibroblast growth factorinducible molecule 14 (Fn14), a member of the TNF receptor superfamily (Haile et al., 2010), and exerts critical control of the inflammatory response and proangiogenic reactions (Burkly et al., 2007; Winkles, 2008). In addition, TWEAK has been reported to promote the levels of pro-inflammatory molecules such as matrix metalloproteinase-9 (MMP-9), intercellular adhesion molecule-1 (ICAM1), and interleukin (IL)-6 (Harada et al., 2002; Kamijo et al., 2008), all of which are involved in the pathogenesis of PDR. Furthermore, considerable evidence suggested a proangiogenic role for TWEAK (Lynch et al., 1999; Donohue et al., 2003; Ho et al., 2004). Therefore, we speculate that the TWEAK/Fn14 pathway may modulate PDR.

The goal of the current study was to determine the expression of the TWEAK/Fn14 pathway in PDR, and to confirm the correlation between TWEAK expression and clinicopathological characteristics of PDR. We also wanted to investigate the regulatory roles of the TWEAK/Fn14 pathway in cell proliferation and collagen synthesis in retinal ARPE-19 cells.

\section{MATERIAL AND METHODS}

\section{Vitreous samples, ARPE-19 cell culture, and TWEAK overexpression}

Vitreous fluid samples (200-500 $\mu \mathrm{L})$ were obtained from 16 PDR patients and 21 type 2 
diabetic (T2D) patients who had undergone vitrectomy. Both groups were enrolled between June 2013 and August 2014 in the Department of Ophthalmology at Jilin University Second Affiliated Hospital. Written consent was given by all patients for the use of vitreous fluid samples in the study. Approval was also obtained from the Ethics Committee of the Second Affiliated Hospital. Detailed characteristics regarding the PDR patients and T2D patients without PDR are outlined in Table 1.

Table 1. Characteristics of patients with T2DM or with PDR.
\begin{tabular}{l|c|c|c}
\hline Characteristics & T2DM (N = 21) & PDR (N = 16) & P value \\
\hline Age (years) & $54.8 \pm 6.2$ & $57.6 \pm 6.8$ & 0.128 \\
\hline Gender & 8 & 9 & 0.2035 \\
\hline Male & 13 & 7 & $<0.01$ \\
\hline Female & $6.6 \pm 3.3$ & $10.8 \pm 4.9$ & 0.129 \\
\hline Duration of DM (years) & $22.48 \pm 2.76$ & $23.52 \pm 2.58$ & 0.046 \\
\hline BMl $\left(\mathrm{kg} / \mathrm{m}^{2}\right)$ & $3.86 \pm 1.85$ & $5.02 \pm 2.14$ & 0.570 \\
\hline CRP & $8.16 \pm 2.10$ & $8.54 \pm 1.21$ & $<0.01$ \\
\hline HbA1c & $1.88 \pm 0.38$ & $2.34 \pm 0.58$ & $<0.01$ \\
\hline Triglycerides & $4.68 \pm 1.16$ & $6.16 \pm 1.37$ & \\
\hline Total cholesterol & & & \\
\hline
\end{tabular}

DM: Diabetes mellitus; BMI: body mass index, CRP: C-reactive protein; HbA1c: hemoglobin A1c.

Following sample collection, vitreous fluids were centrifuged (1000 rpm for $10 \mathrm{~min}, 4^{\circ} \mathrm{C}$ ) to remove cellular debris and were frozen as individual aliquots at $-80^{\circ} \mathrm{C}$ until further use. ARPE-19 cells were purchased from the American Type Culture Collection (ATCC, Manassas, VA, USA) and were cultured in Dulbecco's Modified Eagle Medium + Nutrient Mixture F-12 (DMEM/F-12) (GIBCO, Rockville, MD, USA) supplemented with 10\% fetal bovine serum (FBS) (Invitrogen, Carlsbad, CA, USA), $100 \mathrm{U} / \mathrm{mL}$ penicillin, and $100 \mathrm{mg} / \mathrm{mL}$ streptomycin (CSPC Pharmaceutical Group Limited, Shijiazhuang, China) at $37^{\circ} \mathrm{C}$ and $5 \% \mathrm{CO}_{2}$. Cells at greater than $90 \%$ confluence were sub-cultured at a ratio of $1: 3$.

To overexpress TWEAK in ARPE-19 cells, the human TWEAK coding sequence was amplified (Sinobio, Beijing, China) and cloned into a pcDNA3.1(+) vector (Invitrogen). Enhanced green fluorescence protein (EGFP) coding sequence was also cloned into the vector as a control pcDNA3.1(+). TWEAK-pcDNA3.1(+) or control pcDNA3.1(+) plasmids were transfected into ARPE19 cells with Lipofectamine 2000 (Invitrogen). Cells with successful integration of the target genes TWEAK or EGFP were selected using $1.5 \mathrm{mg} / \mathrm{mL}$ G418 (Thermo Scientific, Rockford, IL, USA), and were maintained in media containing $800 \mathrm{ng} / \mathrm{mL}$ G418.

\section{RNA extraction and quantitative real-time polymerase chain reaction}

Quantitative real-time PCR (qRT-PCR) was performed using QuantiTect SYBR Green PCR Kits (Qiagen, GmbH, Hilden, Germany) following the manufacturer protocol, with GAPDH as an internal control. qPCR was performed on an ABI PRISM 7300 detection system with the following cycling parameters: $95^{\circ} \mathrm{C}$ for $5 \mathrm{~min}$, followed by 40 cycles of $95^{\circ} \mathrm{C}$ for $15 \mathrm{~s}$ and $60^{\circ} \mathrm{C}$ for 1 min. Primers for TWEAK, Fn14, and GAPDH were synthesized by the Sangon company (Shanghai, China). All data are reported as fold change over the internal control, and were calculated using the $\Delta \Delta$ Ct method (Schmittgen and Livak, 2008).

\section{Western blot analysis of TWEAK and Fn14 in vitreous samples or cells}

ARPE-19 cells for western blot assays were collected and lysed with Cell Lysis Solutions 
(Thermo Scientific) containing a protease inhibitor cocktail (Sigma-Aldrich, St. Louis, MO, USA). Both the vitreous samples and the ARPE-19 cell lysis samples were first separated via electrophoresis using a 10\% SDS-PAGE gel, and were transferred to a nitrocellulose membrane (Bio-Rad, Hercules, CA, USA). The membrane was then blocked with $2 \%$ bovine serum albumin (Ameresco, Framingham, MA, USA) overnight at $4^{\circ} \mathrm{C}$. TWEAK, Fn14, and GAPDH were detected with rabbit polyclonal IgG against human TWEAK (Santa Cruz Biotechnology, Santa Cruz, CA, USA), against human Fn14 (Sigma-Aldrich), and human GAPDH (Sinobio), respectively. Protein bands were detected using peroxidase-conjugated secondary antibody against rabbit IgG (Sigma, St. Louis, MO, USA), and were visualized via electrochemiluminescence (ECL) (Amersham, Uppsala, Sweden). The levels of TWEAK and Fn14 have been presented as a percent gray value normalized to GAPDH.

\section{Cell count assay, MTT assay, and colony formation assay}

Growth curves of ARPE-19 (TWEAK+) and ARPE-19 (control) cells were determined via cell count assays. Briefly, ARPE-19 (TWEAK+) and ARPE-19 (control) cells were seeded on 12well plates with an initial cell number of $10^{4}$ cells $/ \mathrm{mL}$. Cells were cultured at $37^{\circ} \mathrm{C}$ for 1,3 or 5 days. Cells in each well were then trypsinized, stained with Trypan blue, and counted in a hemocytometer.

Cellular viability was assayed using the MTT method. ARPE-19 (TWEAK+) and ARPE-19 (control) cells were seeded on 96-well plates, and were allowed to grow to $85-90 \%$ confluence. Media (DMEM/F-12 supplemented with $2 \%$ FBS) were replaced, and the cells were cultured at $37^{\circ} \mathrm{C}$ for another 8,24 or $48 \mathrm{~h}$. This was followed by the addition of MTT (20 $\mu \mathrm{L} /$ well) to each well, and the plates were incubated for an additional $2 \mathrm{~h}$. MTT was then removed, and dimethyl sulfoxide was added to dissolve formazan products. Finally, the OD570 was measured on a microplate spectrophotometer.

For the colony formation assay, 200 or 500 cells per well in each group were seeded onto a 12 -well plate. After 4 days, cell colonies were stained with $0.5 \%$ crystal violet (Beijinghuagong, Beijing, China) and were counted.

\section{Statistical analysis}

Statistical analyses were performed using GraphPad Prism (GraphPad Software, La Jolla, CA, USA). Quantitative results are reported as means \pm standard error of the mean. Comparisons between the two groups (mRNA and protein expression of TWEAK and Fn14, cell number, colony number) were carried out using the Student $t$-test. Statistical significance was reached when $\mathrm{P}<0.05$.

\section{RESULTS}

\section{PDR patients have elevated levels of TWEAK in vitreous fluids}

In the present study, 21 patients with T2DM (without PDR) and 16 patients with PDR were recruited. The clinical characteristics of patients in the two groups are presented in Table 1. There was no significant difference in age, gender, body mass index (BMI), C-reactive protein (CRP), or hemoglobin A1c ( $\mathrm{HbA1c}$ ) between the PDR group and the T2DM group. However, serum levels of both triglycerides and total cholesterol were significantly higher in the PDR patients as compared 
to the control T2DM patients $(P<0.01)$. In addition, duration of DM for the PDR patients was significantly longer as compared with T2DM patient without PDR $(P<0.01)$. In order to determine a possible role of TWEAK in PDR, we examined the vitreous level of TWEAK in each group of patients by using ELISA. As shown in Figure 1A, the TWEAK level in control T2DM patients was $1.64 \pm 0.56 \mathrm{ng} / \mathrm{mL}(\mathrm{N}=21)$, whereas in the PDR patients $(\mathrm{N}=16)$, it was $2.96 \pm 1.14 \mathrm{ng} / \mathrm{mL}(\mathrm{N}=$ 16), which was significant higher $(P<0.001)$. The level of the receptor for TWEAK, Fn14, was also significantly higher in the PDR group as compared to the control group ( $5.37 \pm 1.64$ vs $3.85 \pm 0.78$ $\mathrm{ng} / \mathrm{mL}, \mathrm{P}<0.01$, Figure $1 \mathrm{~B})$. We further examined protein expression of these two molecules via western blot assays. As shown in Figure $1 \mathrm{C}-\mathrm{E}$, there was also a significant difference in the levels of TWEAK and Fn14 of the PDR and control T2DM groups $(P<0.001)$. Therefore, it is possible that TWEAK/Fn14 signaling is upregulated in vitreous fluids of PDR patients.

A

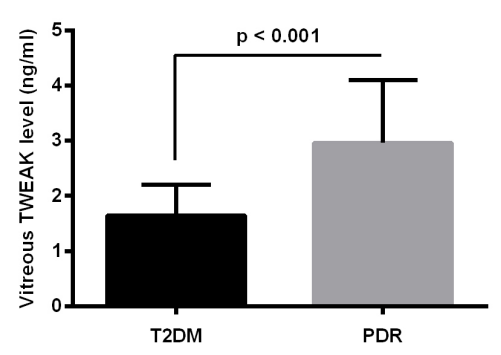

C
B

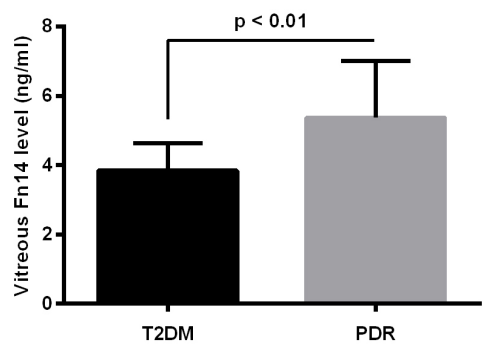

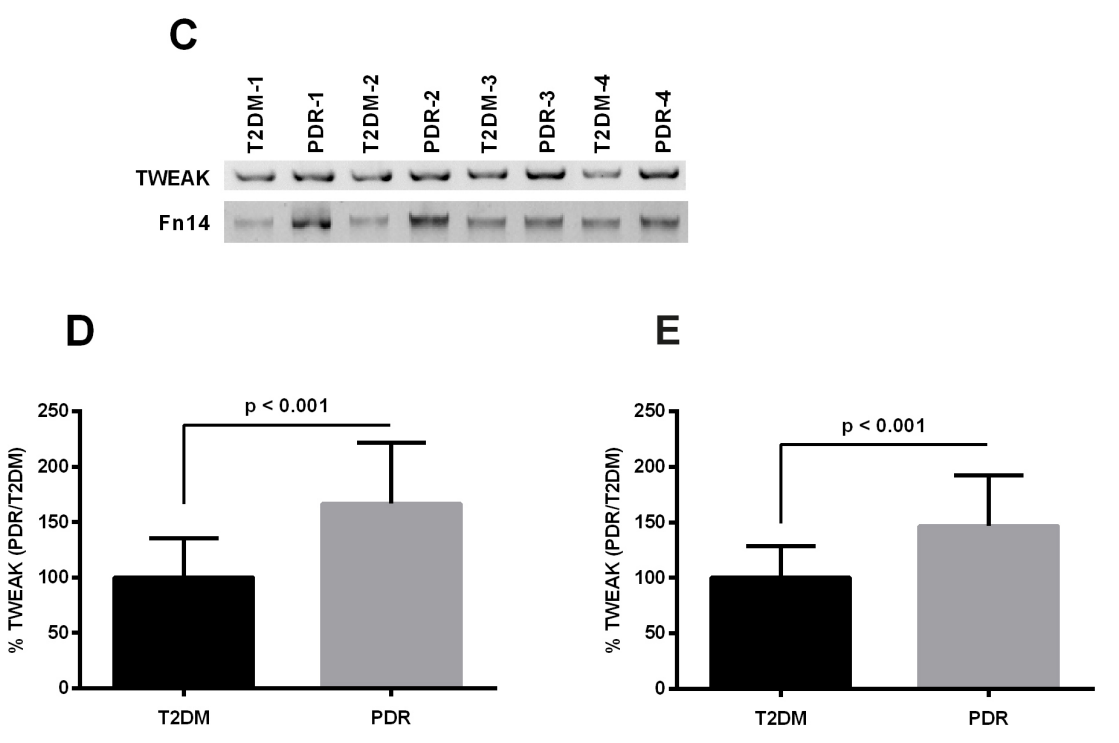

Figure 1. Levels of TWEAK and Fn14 in vitreous fluid of PDR patients. A. B. Enzyme-linked immunosorbent assay (ELISA) for TWEAK and Fn14 in vitreous fluid samples from PDR patients ( $N=16)$, with T2DM patients (without PDR) as control $(\mathrm{N}=21)$; C. Representative western blot analysis of TWEAK and Fn14 in vitreous fluid samples; $D$. $\mathbf{E}$. Percent level of TWEAK (D) or Fn14 (E) in the PDR group, as compared to the T2DM group. Statistical significance is denoted by the $P$ value. 


\section{Construction of a TWEAK-overexpressing ARPE-19 cell line}

We overexpressed TWEAK in retinal ARPE-19 cells in order to determine the role of TWEAK inARPE-19 cell proliferation. Figure 2A shows the strategy used for TWEAK overexpression. The TWEAK-coding sequence was cloned into the pcDNA3.1(+) vector, and ARPE-19 cells were transfected with the recombinant TWEAK-pcDNA3.1(+) plasmid. Successful transfections were selected under the using the antibiotic $\mathrm{G} 418(1.2 \mu \mathrm{g} / \mathrm{mL})$, and positive cell clones were propagated in the presence of $0.8 \mu \mathrm{g} / \mathrm{mL}$ G418. Both mRNA (Figure 2B) and protein (Figure 2C and D) expression of TWEAK was significantly elevated in ARPE-19 (TWEAK+) cells as compared to that in ARPE-19 (control) cells $(P<0.001)$. This effect persisted despite further serial cell passages.

A

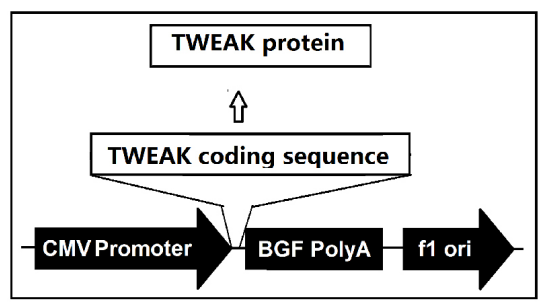

B

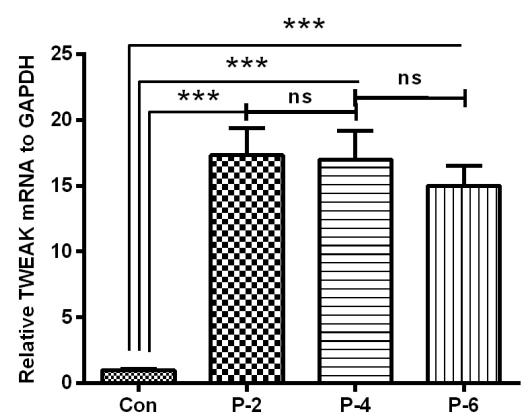

C

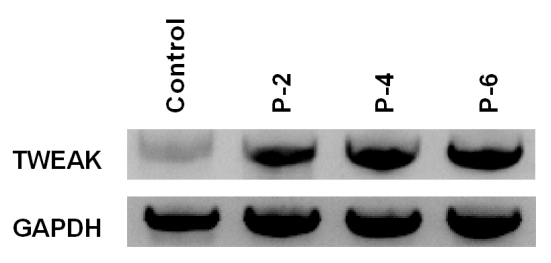

$\mathbf{D}$

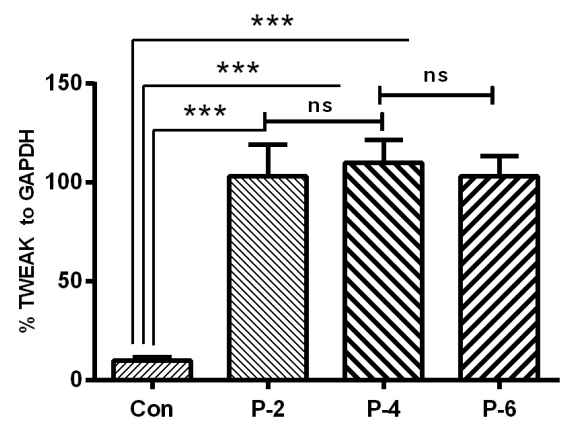

Figure 2. TWEAK overexpression in retinal ARPE-19 cells. A. Schematic diagram of the multiple cloning sites of TWEAK-overexpressing plasmid; B. Relative TWEAK mRNA level in the TWEAK-overexpressing ARPE-19 cells at indicated passages; C. D. Western blot analysis of TWEAK in the serially propagated ARPE-19 (TWEAK+) or ARPE-19 (Con) cells, with glyceraldehyde 3-phosphate dehydrogenase (GAPDH) as an internal control. Quantitative data were averaged for three independent results. ${ }^{* *} \mathrm{P}<0.01,{ }^{* * *} \mathrm{P}<0.001$, ns: no significance.

\section{TWEAK overexpression promotes cell proliferation and collagen synthesis of retinal cells}

To investigate the regulatory role of TWEAK on the proliferation of ARPE-19 cells, we curved the growth of ARPE-19 (TWEAK+) and ARPE-19 (control) cells. As shown in Figure 3A, ARPE-19 (TWEAK+) experienced faster growth as compared to ARPE-19 (control) cells at 3 and 
5 days post inoculation $(P<0.01)$. We also examined the viability of ARPE-19 (TWEAK+) and ARPE-19 (control) cells in media supplemented with 2\% FBS. As indicated in Figure 3B, ARPE-19 (TWEAK+) cells were more viable than ARPE- 19 (control) cells at both 24 and $48 \mathrm{~h}$ post inoculation $(P<0.05)$. To further evaluate the growth difference between the two types of cells, we performed colony-forming assays on these cells. We found that regardless of the number of initially inoculated cells, significantly more colonies were formed by ARPE-19 (TWEAK+) cells as compared to ARPE19 (control) cells (either $P<0.01$ ) (Figure $3 C$ and D). Furthermore, colonies formed by ARPE-19 (TWEAK+) cells were larger than those formed by ARPE-19 (control) cells. Thus, we confirmed that overexpression of TWEAK leads to increased cell proliferation in retinal ARPE-19 cells.

A

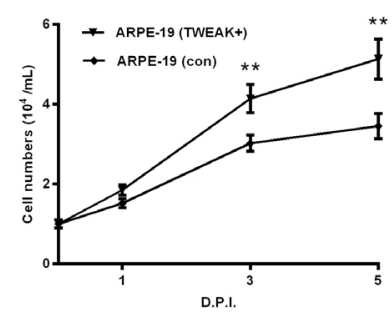

C
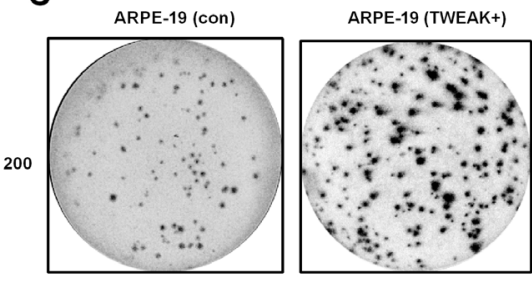

500

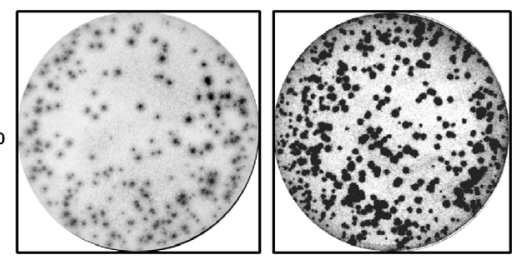

D

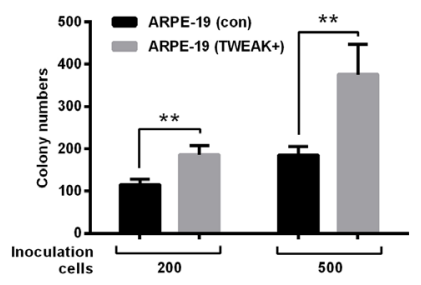

B

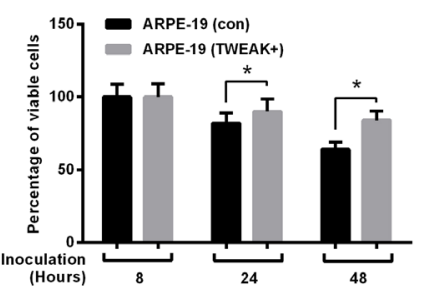


To further confirm the role of TWEAK in the pathogenesis of PDR, we then examined the expression of fibrosis-associated molecules such as $\alpha$-SMA, collagen I, and collagen IV in both ARPE-19 (TWEAK+) and ARPE-19 (control) cells. Western blot analysis (Figure 4A) indicated that there was a significant increase in $\alpha$-SMA (Figure 4B), collagen I (Figure 4C), and collagen IV (Figure 4D) expression in ARPE-19 (TWEAK+) cells as compared to the levels in ARPE-19 (control) cells (either $P<0.001$ ). These observations suggest that TWEAK can increase the production of fibrosis-associated molecules in retinal cells.

A
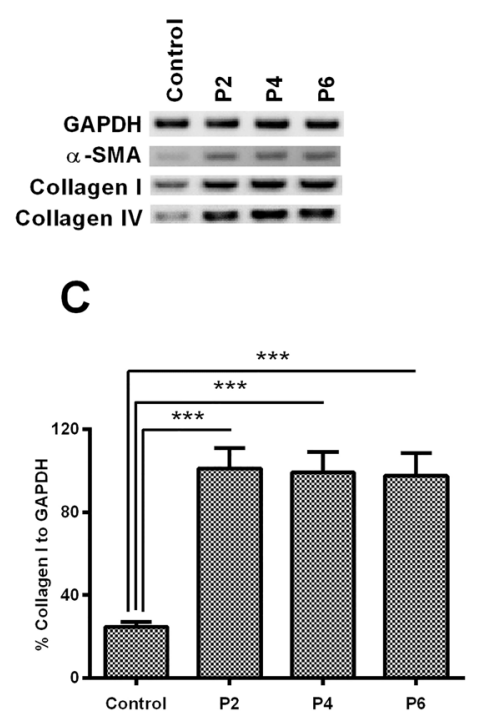

B

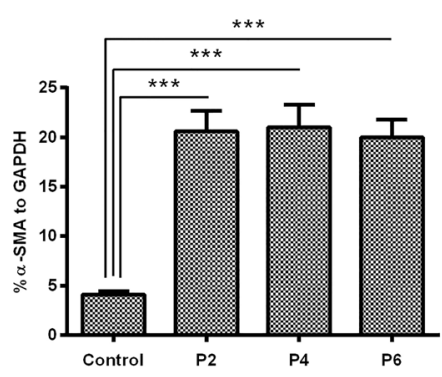

D

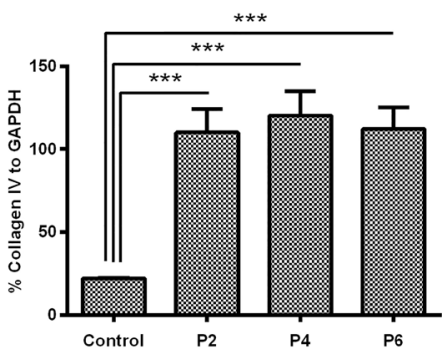

Figure 4. TWEAK overexpression promotes collagen synthesis in retinal cells. A. Western blot analysis of $\alpha$-SMA, collagen I, and collagen IV in ARPE-19 (TWEAK+) (post serial 2, 4 or 6 passages) or in ARPE-19 (Con) cells, with glyceraldehyde 3-phosphate dehydrogenase (GAPDH) serving as an internal control; B.-D. Percent level of $\alpha$-SMA (B), collagen I (C), and collagen IV (D) in ARPE-19 (TWEAK+) (post serial 2, 4 or 6 passages) or in ARPE-19 (Con) cells. Results are reported as means \pm SEM for three independent experiments; ${ }^{* *} P<0.001$, ns: no significance.

\section{DISCUSSION}

It has recently been suggested that TWEAK and Fn14 are upregulated in vitreous fluids of patients with PDR (Abu El-Asrar et al., 2015). Specifically, TWEAK protein was found to be localized in vascular endothelial cells, mononuclear cells, and myofibroblasts in PDR epiretinal membranes (Abu El-Asrar et al., 2015). In addition, TWEAK was reported to be over expressed in synovial fibroblasts from patients with rheumatoid arthritis and psoriatic arthritis (van Kuijk et al., 2010). In the present study, we examined the expression of TWEAK and Fn14 in both PDR and control T2DM patients without PDR. We confirmed that elevated levels of TWEAK and Fn14 
are found in the vitreous fluid from patients with PDR, implying an important regulatory role of TWEAK/Fn14 signaling in the pathogenesis of PDR. Given the relatively low expression of Fn14 in healthy tissues, we speculated that activation of the TWEAK/Fn14 pathway is strictly controlled under normal physiological conditions, and the markedly promoted TWEAK/Fn14 pathway may be associated with the physiopathological status of PDR.

The TWEAK/Fn14 pathway has been confirmed to play important roles in biological processes such as inflammation, angiogenesis, cell death, and fibrosis. Recent reports have indicated that activation of the TWEAK/Fn14 pathway is associated with the clinical severity of autoimmune and inflammatory diseases such as rheumatoid arthritis and systemic lupus erythematosus (Winkles, 2008). This pathway has been found to promote immune responses through its ability to induce cytokines, chemokines, and adhesion molecules (Polavarapu et al., 2005; Kamijo et al., 2008). Accumulating evidence has also demonstrated the proangiogenic (Burkly et al., 2011) and fibrogenic (Winkles, 2008) roles of TWEAK; it has been shown to mediate collagen synthesis and fibrosis in arthritis (Kamata et al., 2006; Perper et al., 2006) as well as cardiac fibrosis (Chen et al., 2012; Novoyatleva et al., 2013). However, the exact role of TWEAK in the pathogenesis of PDR remains unclear. In the present study, we confirmed promotion of the TWEAK/Fn14 pathway in the PDR inflammatory responses. The current study clearly indicated that the overexpression of TWEAK has a large impact on the proliferation of retinal ARPE-19 cells. The increased TWEAK in retinal ARPE-19 cells promoted proliferation and collagen synthesis in retinal cells. These results suggest that TWEAK/Fn14 upregulation in PDR may contribute to PDR progression via induction of pro inflammatory mediators, promotion of angiogenesis, and increased proliferation of retinal cells.

In conclusion, we have found increased expression of the TWEAK/Fn14 pathway in PDR. Our findings imply that TWEAK/Fn14 mediates persistent inflammation and modulation of pathological neovascularization associated with PDR.

\section{Conflicts of interest}

The authors declare no conflict of interest.

\section{ACKNOWLEDGMENTS}

Research supported by a grant from the Second Affiliated Hospital, Jilin University.

\section{REFERENCES}

Abu El Asrar AM, Maimone D, Morse PH, Gregory S, et al. (1992). Cytokines in the vitreous of patients with proliferative diabetic retinopathy. Am. J. Ophthalmol. 114: 731-736. http://dx.doi.org/10.1016/S0002-9394(14)74052-8

Abu El-Asrar AM, Struyf S, Kangave D, Geboes K, et al. (2006). Chemokines in proliferative diabetic retinopathy and proliferative vitreoretinopathy. Eur. Cytokine Netw. 17: 155-165.

Abu El-Asrar AM, De Hertogh G, Nawaz MI, Siddiquei MM, et al. (2015). The tumor necrosis factor superfamily members TWEAK, TNFSF15 and fibroblast growth factor-inducible protein 14 are upregulated in proliferative diabetic retinopathy. Ophthalmic Res. 53: 122-130. http://dx.doi.org/10.1159/000369300

Adamis AP (2002). Is diabetic retinopathy an inflammatory disease? Br. J. Ophthalmol. 86: 363-365. http://dx.doi.org/10.1136/ bjo.86.4.363

Bhavsar AR (2006). Diabetic retinopathy: the latest in current management. Retina 26 (Suppl): S71-S79. http://dx.doi. org/10.1097/00006982-200607001-00016 
Burkly LC, Michaelson JS, Hahm K, Jakubowski A, et al. (2007). TWEAKing tissue remodeling by a multifunctional cytokine: role of TWEAK/Fn14 pathway in health and disease. Cytokine 40: 1-16. http://dx.doi.org/10.1016/j.cyto.2007.09.007

Burkly LC, Michaelson JS and Zheng TS (2011). TWEAK/Fn14 pathway: an immunological switch for shaping tissue responses. Immunol. Rev. 244: 99-114. http://dx.doi.org/10.1111/j.1600-065X.2011.01054.x

Chen HN, Wang DJ, Ren MY, Wang QL, et al. (2012). TWEAK/Fn14 promotes the proliferation and collagen synthesis of rat cardiac fibroblasts via the NF-кB pathway. Mol. Biol. Rep. 39: 8231-8241. http://dx.doi.org/10.1007/s11033-012-1671-3

Citirik M, Kabatas EU, Batman C, Akin KO, et al. (2012). Vitreous vascular endothelial growth factor concentrations in proliferative diabetic retinopathy versus proliferative vitreoretinopathy. Ophthalmic Res. 47: 7-12. http://dx.doi.org/10.1159/000324200

Donohue PJ, Richards CM, Brown SA, Hanscom HN, et al. (2003). TWEAK is an endothelial cell growth and chemotactic factor that also potentiates FGF-2 and VEGF-A mitogenic activity. Arterioscler. Thromb. Vasc. Biol. 23: 594-600. http://dx.doi. org/10.1161/01.ATV.0000062883.93715.37

$\mathrm{Du} \mathrm{JH}, \mathrm{Li}$ X, Li R, Xu L, et al. (2014). Elevation of serum apelin-13 associated with proliferative diabetic retinopathy in type 2 diabetic patients. Int. J. Ophthalmol. 7: 968-973.

Haile WB, Echeverry R, Wu J and Yepes M (2010). The interaction between tumor necrosis factor-like weak inducer of apoptosis and its receptor fibroblast growth factor-inducible 14 promotes the recruitment of neutrophils into the ischemic brain. J. Cereb. Blood Flow Metab. 30: 1147-1156. http://dx.doi.org/10.1038/jcbfm.2009.280

Harada N, Nakayama M, Nakano H, Fukuchi Y, et al. (2002). Pro-inflammatory effect of TWEAK/Fn14 interaction on human umbilical vein endothelial cells. Biochem. Biophys. Res. Commun. 299: 488-493. http://dx.doi.org/10.1016/S0006291X(02)02670-0

Ho DH, Vu H, Brown SA, Donohue PJ, et al. (2004). Soluble tumor necrosis factor-like weak inducer of apoptosis overexpression in HEK293 cells promotes tumor growth and angiogenesis in athymic nude mice. Cancer Res. 64: 8968-8972. http:// dx.doi.org/10.1158/0008-5472.CAN-04-1879

Kamata K, Kamijo S, Nakajima A, Koyanagi A, et al. (2006). Involvement of TNF-like weak inducer of apoptosis in the pathogenesis of collagen-induced arthritis. J. Immunol. 177: 6433-6439. http://dx.doi.org/10.4049/jimmunol.177.9.6433

Kamijo S, Nakajima A, Kamata K, Kurosawa H, et al. (2008). Involvement of TWEAK/Fn14 interaction in the synovial inflammation of RA. Rheumatology (Oxford) 47: 442-450. http://dx.doi.org/10.1093/rheumatology/ken006

Kowluru RA, Zhong Q and Kanwar M (2010). Metabolic memory and diabetic retinopathy: role of inflammatory mediators in retinal pericytes. Exp. Eye Res. 90: 617-623. http://dx.doi.org/10.1016/j.exer.2010.02.006

Lim A, Stewart J, Chui TY, Lin M, et al. (2008). Prevalence and risk factors of diabetic retinopathy in a multi-racial underserved population. Ophthalmic Epidemiol. 15: 402-409. http://dx.doi.org/10.1080/09286580802435179

Lynch CN, Wang YC, Lund JK, Chen YW, et al. (1999). TWEAK induces angiogenesis and proliferation of endothelial cells. J. Biol. Chem. 274: 8455-8459. http://dx.doi.org/10.1074/jbc.274.13.8455

Meleth AD, Agrón E, Chan CC, Reed GF, et al. (2005). Serum inflammatory markers in diabetic retinopathy. Invest. Ophthalmol. Vis. Sci. 46: 4295-4301. http://dx.doi.org/10.1167/iovs.04-1057

Mohan N, Monickaraj F, Balasubramanyam M, Rema M, et al. (2012). Imbalanced levels of angiogenic and angiostatic factors in vitreous, plasma and postmortem retinal tissue of patients with proliferative diabetic retinopathy. J. Diabetes Complications 26: 435-441. http://dx.doi.org/10.1016/j.jdiacomp.2012.05.005

Murugeswari P, Shukla D, Rajendran A, Kim R, et al. (2008). Proinflammatory cytokines and angiogenic and anti-angiogenic factors in vitreous of patients with proliferative diabetic retinopathy and eales' disease. Retina 28: 817-824. http://dx.doi. org/10.1097/lAE.0b013e31816576d5

Novoyatleva T, Schymura Y, Janssen W, Strobl F, et al. (2013). Deletion of Fn14 receptor protects from right heart fibrosis and dysfunction. Basic Res. Cardiol. 108: 325. http://dx.doi.org/10.1007/s00395-012-0325-x

Patel JI, Tombran-Tink J, Hykin PG, Gregor ZJ, et al. (2006). Vitreous and aqueous concentrations of proangiogenic, antiangiogenic factors and other cytokines in diabetic retinopathy patients with macular edema: Implications for structural differences in macular profiles. Exp. Eye Res. 82: 798-806. http://dx.doi.org/10.1016/j.exer.2005.10.002

Pennock S and Kazlauskas A (2012). Vascular endothelial growth factor A competitively inhibits platelet-derived growth factor (PDGF)-dependent activation of PDGF receptor and subsequent signaling events and cellular responses. Mol. Cell. Biol. 32: 1955-1966. http://dx.doi.org/10.1128/MCB.06668-11

Perper SJ, Browning B, Burkly LC, Weng S, et al. (2006). TWEAK is a novel arthritogenic mediator. J. Immunol. 177: 26102620. http://dx.doi.org/10.4049/jimmunol.177.4.2610

Polavarapu R, Gongora MC, Winkles JA and Yepes M (2005). Tumor necrosis factor-like weak inducer of apoptosis increases the permeability of the neurovascular unit through nuclear factor-kappa B pathway activation. J. Neurosci. 25: 1009410100. http://dx.doi.org/10.1523/JNEUROSCI.3382-05.2005

Rizyal A (2004). Ocular manifestations in diabetes mellitus: an experience at Nepal Medical College Teaching Hospital. Nepal Med. Coll. J. 6: 136-138. 
Schmittgen TD and Livak KJ (2008). Analyzing real-time PCR data by the comparative C(T) method. Nat. Protoc. 3: 1101-1108. http://dx.doi.org/10.1038/nprot.2008.73

Sethi G, Sung B and Aggarwal BB (2009). Therapeutic potential of VEGI/TL1A in autoimmunity and cancer. Adv. Exp. Med. Biol. 647: 207-215. http://dx.doi.org/10.1007/978-0-387-89520-8 15

Suzuki Y, Nakazawa M, Suzuki K, Yamazaki H, et al. (2011). Expression profiles of cytokines and chemokines in vitreous fluid in diabetic retinopathy and central retinal vein occlusion. Jpn. J. Ophthalmol. 55: 256-263. http://dx.doi.org/10.1007/ s10384-011-0004-8

Symeonidis C, Papakonstantinou E, Androudi S, Rotsos T, et al. (2011). Interleukin-6 and the matrix metalloproteinase response in the vitreous during proliferative vitreoretinopathy. Cytokine 54: 212-217. http://dx.doi.org/10.1016/j.cyto.2011.02.001

van Kuijk AW, Wijbrandts CA, Vinkenoog M, Zheng TS, et al. (2010). TWEAK and its receptor Fn14 in the synovium of patients with rheumatoid arthritis compared to psoriatic arthritis and its response to tumour necrosis factor blockade. Ann. Rheum. Dis. 69: 301-304. http://dx.doi.org/10.1136/ard.2008.090548

Winkles JA (2008). The TWEAK-Fn14 cytokine-receptor axis: discovery, biology and therapeutic targeting. Nat. Rev. Drug Discov. 7: 411-425. http://dx.doi.org/10.1038/nrd2488

Zhang Z and Li LY (2012). TNFSF15 modulates neovascularization and Inflammation. Cancer Microenviron. 5: 237-247. http:// dx.doi.org/10.1007/s12307-012-0117-8 